\title{
Imágenes Organizacionales en Empresas Brasileñas: DETECCIÓN Y ANÁLISIS CON TÉCNICAS DE MINERÍA DE DATOS
}

\author{
Organizational Images in Brazilian Companies: detection and \\ analysis with data mining
}

Eliana Rocío Rocha Blanco

Profesora del Departamento de Administración de Empresas de la Universidad de Cantabria - Santander - España. E-mail: rochar@ unican.es

\section{Angel Cobo Ortega}

Profesor del Departamento de Matemática Aplicada y Ciencias de la Computación de la Universidad de Cantabria - Santander -

España.E-mail: acobo@unican.es

\section{Adolfo Alberto Vanti}

Profesor del programa de Doutorado y Mestrado em Contabilidade. Universidade do Vale do Rio dos Sinos (UNISINOS) - São

Leopoldo - RS - Brasil.E-mail: avanti@unisinos.br

\section{Silvio Johann}

Profesor-invitado cursos MBA de la Fundação Getúlio Vargas (FGV) - Rio de Janeiro - RJ - Brasil. E-mail: prof.silvio.fgv@terra.com.br

\section{Resumen}

Las imágenes organizacionales permiten visualizar el contexto empresarial en el que las organizaciones están inmersas, definiendo modelos comportamentales que respondan a su cultura organizacional. Este trabajo se inicia con el enfoque de Morgan (1986) y se utilizaron 35 cuestiones para la identificación de metáforas en una muestra de empresas del estado de Rio Grande do Sul. La utilización de técnicas de data mining permitió identificar las imágenes que con mayor claridad están presentes en la muestra. Los análisis realizados resultan de gran importancia para la gestión de la cultura y del comportamiento empresarial, permitiendo trabajar mejor en el logro de los objetivos organizacionales.

Palavras-chave: Imágenes Organizacionales. Cultura Organizativa. Minería de Datos. Clustering.

\section{Abstract}

The organizational images allow visualizing the business context in which organizations are embedded, and define behavioral models that respond to their organizational culture. This work begins with the approach of Morgan (1986) and uses 35 questions to identify metaphors in a sample of companies in the state of Rio Grande do Sul. Quantitative analysis was performed by data mining techniques. The techniques identified images that are present in the sample. Analyzes are importance for the management of culture and business behavior, due to the identification of images may achieve organizational objectives.

Keywords: Organizational Images. Organizational Culture. Data Mining. Clustering. 


\section{INTROducCión}

Morgan presenta las imágenes organizacionales o metáforas como una herramienta de investigación que permite entender mejor a las organizaciones, identificar sus enfoques organizativos y analizar la realidad de la organización desde una multiplicidad de puntos de vista (MORGAN, 1986). En su actualizada edición de 2006 de su trabajo "Images of Organization", Morgan argumenta que a pesar del desarrollo constante de las tecnologías de la información y las comunicaciones electrónicas en un contexto global y de sus efectos sobre los modelos cambiantes de las organizaciones, y a pesar de la aparente transformación de estructuras burocráticas centralizadas en estructuras descentralizadas más fluidas, el enfoque original de las imágenes organizacionales sigue siendo pertinente y aplicable en el campo de los estudios organizacionales. (MORGAN, 2006)

Las siete imágenes organizacionales o metáforas planteadas por Morgan, y que serán objeto de análisis en este trabajo, son las denominadas: máquinas, organismos, sistema político, cerebro y cultura, instrumentos de dominación, flujo y transformación y, finalmente, prisión psíquica. La metáfora máquina o mecanicismo (M) se puede asociar a conceptos como burocracia, eficiencia, orden, puntualidad, estandarización y control. La metáfora organismo $(\mathrm{O})$ guarda relación con necesidades humanas, adaptación y evolución sistémica. El sistema político (SP) enfatiza los intereses y derechos, el poder y principalmente la gestión de conflictos. Cerebro y cultura $(\mathrm{C})$ se relaciona con conceptos como aprendizaje, retroalimentación, trabajo en red, valores y creencias. Instrumentos de dominación (ID) se vincula a alienación, represión, imposición de valores, fuerza y prevalencia de los intereses de la empresa. El flujo y transformación (FT) es una metáfora que considera fuertemente cambios constantes, auto-organización, caos, complejidad y propiedades emergentes. Finalmente, la prisión psíquica $(\mathrm{PP})$ ve una organización como cárceles psíquicas. En la próxima sección se describirán con más detalle los principales rasgos representativos de cada una de estas metáforas organizacionales.

El objetivo principal de este trabajo de investigación es explorar la posibilidad de la utilización de las técnicas de minería de datos para detectar y analizar imágenes organizacionales, alcanzando los objetivos específicos de diagnosticar las metáforas o imágenes, presentar un método robusto de operación de minería de datos, y por último, analizar agrupamientos de datos para identificar las imágenes de mayor presencia en empresas competitivas del estado de RS, extremo sur de Brasil.

Para lograr ese objetivo, la metodología aplicada ha seguido el paradigma positivista cuantitativo, debido a los algoritmos empleados para el análisis numérico de datos. Sin embargo, para recopilar esos datos se requirió un proceso de entrevistas con responsables de diferentes departamentos de las organizaciones de la muestra, que pasó por un enfoque inicial del paradigma interpretativista o fenomenológico, debido a la necesidad de analizar/interpretar las diferentes cuestiones dentro del contexto comportamental de su organización.

El enfoque original de Morgan (1986) está basado en una interpretación cualitativa de imágenes y genera una variación importante de sus significados en función de las motivaciones y percepciones de cada individuo. Con el método desarrollado en este trabajo, ha sido posible que el enfoque teórico original se pueda acercar a un análisis positivista, disminuyendo el distanciamiento con respecto a la interpretación cualitativa original. Todo ello gracias a la utilización de técnicas positivistas de minería de datos (data mining) como las técnicas de clustering; técnicas que permiten realizar agrupamientos automáticos y encontrar patrones de comportamiento difíciles de identificar con un método cualitativo clásico, sustentado exclusivamente en interpretaciones de individuos.

El proceso de descubrimiento de conocimiento con técnicas de minería de datos ha pasado por cuatro etapas básicas: determinación de objetivos, pre-procesamiento, transformación de datos, uso de algoritmos y finalmente, el análisis y evaluación de resultados.

Los análisis efectuados han permitido determinar las imágenes más relevantes en la muestra, obteniendo además una jerarquización de asociaciones secundarias de imágenes. Los resultados encontrados resultan interesantes, pueden ser utilizados para la toma de decisiones, y también para ser tenidos en cuenta en los procesos de capacitación y entrenamiento del personal de cada organización. También es posible obtener una noción de lo que falta para que la empresa alcance la 
imagen "flujo y transformación", imagen que Morgan, ya en la década de los 90, anticipaba como la más adecuada en la era de la tecnología de la información, y la que permite aumentar de manera más significativa la competitividad de la empresa.

El estudio de casos ha correspondido a estudiantes de Administración y Contabilidad que actúan en empresas en el estado del RS. En cada una de las empresas seleccionadas, y con objeto de comprobar la percepción sobre la imagen que proyecta cada una, se realizaron 4 entrevistas con empleados y cargos directivos con conocimiento del estilo de gestión y administración de su correspondiente organización. En cada una de las entrevista se realizó un cuestionario de 35 preguntas iniciado en Johann (2004), siendo posteriormente tabulados todos los datos junto con los perfiles de cada una de las empresas y de los entrevistados. Todos esos datos fueron procesados y almacenados inicialmente en una hoja de cálculo. Algunos de los cuestionarios fueron excluidos por indebida interpretación del instrumento. Más adelante se detallarán los aspectos más relevantes del estudio realizado.

\section{Cultura Organizativa e Imágenes de las Organizaciones}

Los gestores trabajan excesivamente en nuevas prácticas para lograr un patrón competitivo y estable para la empresa, sin embargo no prestan, en ocasiones, especial atención a la cultura corporativa, los valores compartidos por los empleados, sus creencias y los comportamientos que emergen del éxito de las organizaciones (SCHEIN, 1990). Cuando una cultura no funciona bien es necesario recuperar éxitos pasados y revitalizar hábitos productivos, gestionando los conflictos y las anomalías de manera que se recupere el propósito esencial de la organización. De lo contrario, emerge la contracultura, un comportamiento segregado de funciones que son poco productivas, generando de esta manera sub-culturas en los departamentos empresariales.

$\mathrm{El}$ problema es que la realidad organizacional en ocasiones no contempla la valorización funcional y considera al empleado como un simple y cambiable recurso. De acuerdo con Minarelli (1995) las empresas saben de este hecho y de los riesgos que puede oca- sionar la reducción de lealtad del empleado. Cuando una empresa presenta alto grado de valores y creencias compartidas por los profesionales, posee una cultura densa, que en la visión de Freitas (1991) se configura en una co-existencia de poca discordia o vaguedad referente al posicionamiento personal y a la toma de decisiones.

Por otro lado, la contracultura aglutina grupos o subgrupos que repulsan la representación, el posicionamiento de la organización. Genera una oposición disimulada frente a los valores dominantes y/o a la estructura de poder de la empresa. Para Freitas (1991), esas formas de resistencia y conflictos generan brechas en el sistema de poder formal. La cultura densa y contracultura pueden ser estudiadas a través del enfoque antropológico (FLEURY; FISCHER, 1996) para entender la práctica social y organizacional, pero también con el enfoque de imágenes o metáforas organizacionales. En este trabajo se ha añadido un análisis matemático y computacional sobre diagnósticos de imágenes en diferentes organizaciones (JOHANN, 2008). Con esto diferentes conclusiones se han podido generar para mejorar la eficiencia de cada empresa estudiada.

Dentro de las organizaciones, cada uno de sus integrantes puede tener una percepción propia sobre el enfoque organizativo de su empresa. La identidad organizacional también puede residir en imágenes metafóricas interiorizadas en los miembros de la organización (TABER, 2007). El uso de metáforas para describir los fenómenos de una organización se basa en la premisa de que el pensamiento humano en gran medida está basado en imágenes, y no en el lenguaje (PINKER, 1994). Las imágenes, o metáforas organizacionales, permiten identificar el enfoque organizativo, realizando una síntesis de todos los modelos que han subyacido a los distintos enfoques de una organización, con el propósito de entender y poner en relieve ciertos aspectos importantes como la forma en son diseñadas o cómo son dirigidas (MORGAN, 1986). Estas metáforas son interpretaciones de acciones establecidas en procesos de negocios que definen una forma de conocer y comprender la dinámica organizacional

En todos los aspectos de la vida cotidiana se define la realidad de un individuo en términos de metáforas, para proceder a la toma de decisiones sobre la base de las mismas. Las imágenes y metáforas no 
son sólo construcciones interpretativas o formas de ver, sino que también proporcionan un marco para la acción. Su uso proporciona ideas que a menudo permiten actuar de manera anticipada, sacar conclusiones, establecer objetivos; permitiendo conocer en el ámbito de las organizaciones sus limitaciones, la generación de conocimiento e información valiosa. Morgan propone el uso de estas imágenes como un instrumento útil para comprender mejor la dinámica de una organización, sin embargo, advierte que aunque todas las teorías de la organización están basadas en imágenes implícitas o metáforas, estás nos permiten ver, entender e imaginar situaciones de una manera parcial. Las metáforas favorecen el entendimiento, pero también pueden distorsionarlo; tienen fortalezas, pero también limitaciones; crean formas de ver, pero también formas de no ver. En definitiva, como Morgan establece, no puede haber una simple teoría o metáfora que ofrezca una visión completa bajo todos los puntos de vista.

Las siete metáforas organizacionales propuestas por Morgan (1986) se describen a continuación. Lo Marco 1 muestra de forma resumida algunas de sus características más relevantes.

Imagen 1 (Máquina o mecanicismo): La mecanización toma el mando en una organización. Se espera que una organización tenga una precisión mecánica a tal punto que actúe como una máquina en todos los aspectos y que los empleados se comporten como si fueran piezas de esa máquina. Cuando las cosas van bien en una organización se dice que la organización está "funcionando como un reloj", y cuando no es así, se dice "las cosas necesitan arreglarse". Se espera que los empleados de la organización lleguen al trabajo a una hora determinada, cumplan un conjunto predeterminado de funciones, descansen a las horas señaladas y además todo ello se realice de una forma rutinaria, eficiente, exacta y predecible. Algunos principios básicos extraídos de la teoría clásica de una organización por expertos en administración empresarial para esta metáfora son: la planificación, disciplina, unidad de mando, organización, orden, iniciativa, coordinación y control. Se trata de delegar toda la responsabilidad de la organización del trabajo que ha de hacer el trabajador al directivo, utilizar métodos científicos para determinar el modo más eficiente de realizar el trabajo, seleccionar la mejor persona para realizar el trabajo analizado, instruir al trabajador para hacer el trabajo eficientemente. Estas características también son confirmadas por Hellriegel y Slocum (2004) y referenciadas en toda la administración científica. (TAYLOR, 1980)

Imagen 2 (Organismo): Se considera a una organización como un sistema vivo o como una especie de organismo biológico; los individuos y grupos trabajan más eficazmente cuando sus necesidades están satisfechas. En esta imagen existe un ambiente del cual dependen para satisfacer sus necesidades y la adaptación de la organización al entorno. Por ejemplo, una organización puede trabajar más eficazmente en entornos que están protegidos o que son estables, u otras trabajan mejor en entornos altamente tecnológicos. Cuando los empleados realizan bien su trabajo, se sienten motivados o útiles por conseguir recompensas que satisfacen sus necesidades personales y al mismo tiempo se les proporciona autonomía, responsabilidad y reconocimiento. Estas ideas proporcionan un marco de desarrollo para la gestión de recursos humanos.

Imagen 3 (Sistema Político): Se considera a una organización como un sistema político o de gobierno. Las características principales de esta imagen son los intereses, conflictos y poder. Las organizaciones pueden ser altamente autoritarias o también moderadamente democráticas. En la vida cotidiana un ciudadano es libre de mantener sus ideas $\mathrm{u}$ opiniones, tomar sus propias decisiones y ser tratado como igual; en el caso de la empresa, al empleado le son negados esos derechos; sus únicos derechos democráticos descansan en la libertad de encontrar otro empleo y marcharse. Es también considerada un sistema pluralista. Las organizaciones buscan la manera de lograr un orden y dirección entre gente con diversidades potenciales y en un continuo conflicto de intereses.

Imagen 4 (Cerebro y cultura): Se considera a una organización en esta imagen como un cerebro y como cultura. Las organizaciones deben ser capaces de ser flexibles, resistentes y con inventiva como lo es un cerebro. Las organizaciones son sistemas de información, comunicación y toma de decisiones, deben tener estrategias y estar motivadas para la creatividad y la inventiva cotidiana, a través por ejemplo, de la incorporación de equipos de planificación o unidades centralizadas de investigación y de tomas de decisión. Otros autores utilizan el término cibernética para referirse a esta imagen (CAPRA, 1996) y argumentan que la metáfora cultura está realmente presente en todo el 
conjunto de imágenes, la consideración de una organización como cultura, es algo fluctuante, dependerá del estado de desarrollo de la sociedad. Por todo ello, en la parte práctica o aplicada del presente trabajo ya no se utiliza la denominación "cultura" como imagen independiente. Los orígenes de esta metáfora se remontan a los sistemas abiertos del biólogo Von Bertalanffy (1972) y a los principios de la homeostasia, de búsqueda de equilibrio y del feedback. (KATZ; KAHN, 1978)

Imagen 5 (Instrumento de dominación): Esta imagen es la más desagradable, considerando a una organización como instrumento de dominación. Siempre se ha asociado a una organización con procesos de dominación social, donde individuos o grupos han encontrado el medio de imponer su voluntad a los demás. Como por ejemplo la explotación de empleados, utilizando lo que necesitan de ellos y eliminando al resto, aunque actualmente se haga de forma más sutil que en la antigüedad. Esto se hace evidente en la forma de estructurar las oportunidades de trabajo, en el modo de formular los daños en las situaciones laborales, los accidentes de trabajo, las enfermedades profesionales y en el modo en como las organizaciones perpetúan las estructuras y prácticas que promueven el stress mental y social.

Imagen 6 (Flujo y Transformación): La organización como cambio y transformación, es vista como un sistema dinámico. Los cambios se generan en el entorno y se ven como retos importantes a los que la organización debe enfrentarse. Las organizaciones que responden a esta metáfora intentan penetrar en la naturaleza y origen del cambio, así como comprender su lógica. Los sistemas son como redes en las que el éxito da la organización está en el trabajo conjunto. Las organizaciones "flujo y transformación" pueden ser consideradas como parte integrante de su marco-entorno. Este tipo de empresa entiende que su sobrevivencia a largo plazo será alcanzada con el entorno donde está operando, jamás contra el mismo.

Imagen 7 (Prisión psíquica): La organización como cárceles psíquicas. Algunas organizaciones y sus miembros quedan atrapados por suposiciones imperfectas del mundo, falsas suposiciones, normas operativas incuestionadas y otras numerosas premisas. Es considerado por Morgan la anti-organización.

\begin{tabular}{|c|c|}
\hline $\begin{array}{c}\text { Organización } \\
\text { сомO... }\end{array}$ & Características \\
\hline Máquina (M) & $\begin{array}{l}\text { Burocracia, eficiencia, mantenimiento, orden, } \\
\text { puntualidad, una pieza más en el engranaje } \\
\text { del organismo, programas, entradas y salidas, } \\
\text { estandarización, producción, diseño, medición } \\
\text { y control. }\end{array}$ \\
\hline Organismo (O) & $\begin{array}{l}\text { Necesidades humanas, sistemas vivos, } \\
\text { condiciones ambientales, adaptación, ciclos } \\
\text { de vida, reciclaje, necesidades, homeostasis } \\
\text { (Conjunto de fenómenos para el equilibrio del } \\
\text { organismo), evolución, supervivencia del más } \\
\text { apto, salud, enfermedad. }\end{array}$ \\
\hline $\begin{array}{l}\text { Sistema } \\
\text { Político (SP) }\end{array}$ & $\begin{array}{l}\text { Intereses y derechos, poder, agendas ocultas, } \\
\text { autoridad, alianzas, línea del partido, censura, } \\
\text { dirigentes, gestión de conflictos. }\end{array}$ \\
\hline Cerebro (C) & $\begin{array}{l}\text { Aprendizaje, procesamiento de la información } \\
\text { en paralelo, control distribuido, mentalidad, } \\
\text { inteligencia, retroalimentación, variedad, } \\
\text { conocimientos, redes, sociedad, valores, } \\
\text { creencias, leyes, ideología, rituales, diversidad, } \\
\text { tradiciones, historia, servicios, visión y misión } \\
\text { compartidas, entendimiento, cualidades, } \\
\text { familias, diferentes grupos de personas tienen } \\
\text { diferentes modos de vida. }\end{array}$ \\
\hline $\begin{array}{l}\text { Instrumento de } \\
\text { dominación (ID) }\end{array}$ & $\begin{array}{l}\text { Alienación, represión, imposición de valores, } \\
\text { cumplimiento, carisma, mantenimiento del } \\
\text { poder, fuerza, explotación, divide y vencerás, } \\
\text { discriminación, interés de las empresas. }\end{array}$ \\
\hline $\begin{array}{l}\text { Flujo y } \\
\text { Transformación } \\
\text { (FT) }\end{array}$ & $\begin{array}{l}\text { Cambio constante, equilibrio dinámico, flujo, } \\
\text { auto-organización, sabiduría sistémica, caos, } \\
\text { complejidad, efecto mariposa, propiedades } \\
\text { emergentes, dialéctica, paradoja. }\end{array}$ \\
\hline $\begin{array}{l}\text { Prisión } \\
\text { psíquica (PP) }\end{array}$ & $\begin{array}{l}\text { Procesos conscientes e inconscientes, represión } \\
\text { y de regresión, ego, negación, proyección, } \\
\text { mecanismos de supervivencia y de defensa, } \\
\text { dolor y principio del placer, disfunción, } \\
\text { workaholis (Adicción al trabajo). }\end{array}$ \\
\hline
\end{tabular}

Marco 1: Imágenes organizacionales

Fuente: Elaborado por los autores de este artículo

Los trabajos de Morgan sobre imágenes organizacionales han sido objeto de un profundo estudio bajo diferentes ópticas. El autor advierte que los cambios del entorno en el que operan las organizaciones pueden afectar o impactar de manera más significativa en unas imágenes en detrimento de otras. Así, en una teleconferencia con doctorandos en noviembre de 1996, afirmaba que ya en la década de los 90 se estaba viviendo en medio de una revolución organizacional caracterizada por el uso de las tecnologías de la información. 
Esta revolución favorece los sistemas organizacionales más abiertos y complejos, pero también inciertos e incluso caóticos que se alejan de puntos de equilibrio, situación con la que habitualmente las personas no se encuentran cómodas. El propio autor entonces prevé que las organizaciones deberían evolucionar hacia imágenes similares a la que presenta el capítulo 8 de su obra: la imagen que se denomina "flujo y transformación".

Lógicamente, algunas organizaciones poseen metáforas más acentuadas que otras. En el enfoque de Johann (2004) las imágenes de la organización, al ser percibidas por las personas, pueden ser en cierto modo medidas con métodos de investigación científica apropiados, eso es precisamente lo que se pretende con este trabajo, en el que se utilizan técnicas de minería de datos para tratar de identificar las imágenes percibidas por los miembros de distintas organizaciones.

\section{Proceso de Descubrimiento de Conocimiento con Minería de Datos}

En la actualidad existen diferentes procesos o estrategias que permiten extraer y crear nuevo conocimiento mediante el análisis de los grandes volúmenes de información que generan las organizaciones. La minería de datos o data mining (DM) es una de esas estrategias y comprende un conjunto de algoritmos y métodos que permiten explorar y analizar de forma automática o semi-automática grandes volúmenes de información (WITTEN et al., 2005). Las técnicas de minería de datos posibilitan la predicción de co- nocimiento y comportamientos, generan pronósticos, identifican tendencias o cambios en esas tendencias, detectan patrones de comportamiento y también permiten descubrir relaciones entre la información para mejorar las ventajas competitivas y optimizar la toma de decisiones en las organizaciones. Las ventajas que obtienen las organizaciones utilizando estas técnicas son muchas, desde el incremento de ganancias hasta la maximización de su eficiencia operativa, así como también permite reducir costes, generar nuevas oportunidades de negocio, estimar el potencial económico de los clientes, mejorar la satisfacción de los mismos, descubrir nuevos segmentos de clientes potenciales, etc.

Un proyecto de minería de datos debe completar cuatro etapas básicas; la primera consiste en determinar los objetivos que se quieren alcanzar y en obtener los datos a procesar. La etapa de pre-procesamiento consistirá en limpiar, transformar y reducir los datos. Las operaciones que transforman los datos pueden ser la reducción o aumento de dimensionalidad, discretización (conversión de un valor numérico a un valor nominal ordenado) y normalización (transformación de los valores de las variables cuando tienden a tener rangos distintos). Esta etapa es la que consume más de la mitad del tiempo del esfuerzo de desarrollo. La siguiente etapa consiste en aplicar la técnica de explotación de datos, determinando el modelo a utilizar, realizando análisis estadísticos y visualizando gráficamente los datos para tener una primera aproximación. Finalmente, la última etapa es la de análisis y evaluación de resultados obtenidos, verifica si los resultados son coherentes y los coteja con lo analizado estadística y gráficamente. (FERRI et al., 2004)

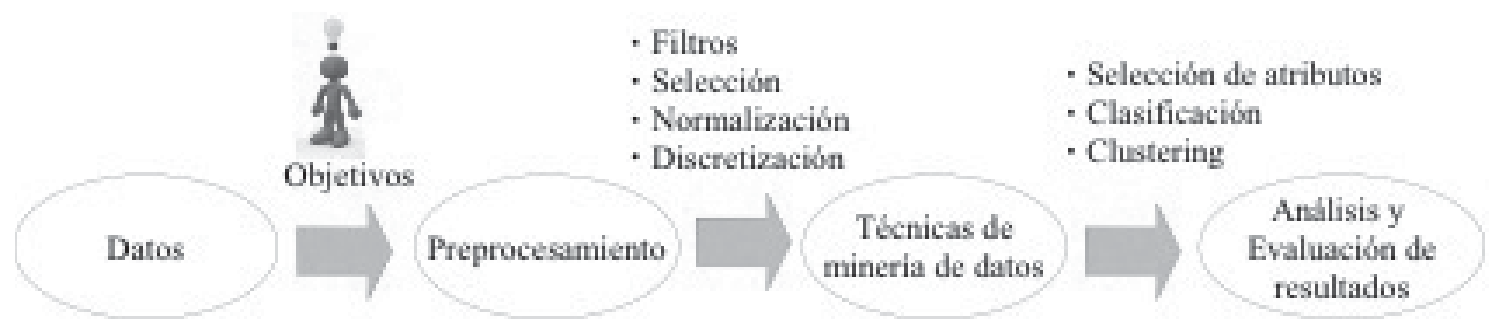

Figura 1. Fases de un proyecto de minería de datos

Fuente: Adaptado Ferri et al. (2004) 


\section{Caso de Estudio}

A continuación se describen cada una de las etapas del proyecto de minería de datos abordado en este trabajo. En primer lugar se determinan los objetivos a alcanzar, posteriormente se realizan todas las operaciones de la etapa de pre-procesamiento y preparación de datos, se aplican las técnicas de explotación propias de minería de datos; y para finalizar, se analizan los resultados obtenidos tras aplicar las estrategias.

\subsection{Determinación de los Objetivos}

El objetivo de este trabajo es la identificación de rasgos o indicadores que puedan ser utilizados para tratar de identificar de forma automática las imágenes o metáforas organizacionales de Morgan asociadas a una organización. En concreto se trata de utilizar técnicas de minería de datos para realizar procesos de clustering o clasificación no supervisada de organizaciones y analizar las características de los grupos obtenidos, tratando de descubrir la existencia de relaciones o patrones de comportamiento.

Se tomará como referencia datos extraídos de una encuesta realizada a un grupo de 119 empleados de 35 empresas diferentes que operan en el Estado de Rio Grande do Sul (Brasil). A la hora de seleccionar la muestra de empresas a analizar, se buscó una muestra variada y que pudiera ser representativa del perfil de las organizaciones que operan en el estado de Rio Grande do Sul; se buscó variabilidad tanto en aspectos de tamaño de las empresas como de sectores en los que operan. Evidentemente, este estudio consideró una muestra de tamaño reducido y por esto hay limitaciones para generar conclusiones sectoriales definitivas del estudio, pero este tipo de análisis puede ser objeto de una investigación posterior. Incluso se plantea como línea futura de investigación la comparación de la presencia de las metáforas por ámbitos geográficos, tanto dentro de Brasil como la comparación con empresas que operan en Europa.

Dentro de las 35 empresas analizadas, nos encontramos con un reparto prácticamente a partes iguales según su tamaño, así 11 de las empresas tienen la consideración de pequeñas empresas, 13 son medianas $y$, finalmente, otras 11 pueden considerarse empresas grandes. En cuanto a los sectores en los que operan, el sector más representativo es el sector servicios, con un número importante de empresas (11) que desarrollan labores en el campo contable, fiscal y financiero. Los siguientes sectores más representados en la muestra corresponden al sector de transporte e industria auxiliar del automóvil (5 empresas), la industria química y farmacéutica (5 empresas) y la industrial textil y del calzado (4 empresas). El resto de empresas desarrollan actividades varias como la construcción civil, comercio exterior y minorista, alimentación o metalurgia. El hecho de tener un número reducido de empresas por sector limita extraer conclusiones muy significativas sobre la vinculación de imágenes con sectores productivos o ramas de actividad, pero establece una relación metodológica robusta que puede ser utilizada en futuros trabajos.

Como norma general se entrevistaron a cuatro empleados de cada empresa con conocimiento global de los aspectos organizacionales. En algunos casos, el número de entrevistados fue menor, pero siempre se quiso contrastar la imagen percibida por más de un empleado de la organización. Todas las entrevistas fueron realizadas durante el mes de marzo de 2011. La encuesta estaba configurada por 35 afirmaciones sobre aspectos organizativos a las que los diferentes empleados debían proceder a una evaluación en una escala discreta de valores entre 1 y 4 , de acuerdo a los siguientes criterios: 4 si existe fuerte presencia, $3 \mathrm{si}$ existe presencia razonable, 2 si existe poco impacto; y 1 si no existe prácticamente ninguna presencia. El anexo A muestra la encuesta utilizada.

El cuestionario ha sido desarrollado a partir del trabajo de Johann (2004) tomando como referencia los trabajos de Morgan, y buscando una estrategia de agrupación de cuestiones de acuerdo a las características de las imágenes propuestas por el propio autor. A cada imagen organizacional se le asociaron las cinco afirmaciones de la encuesta más relacionadas, a priori, con el perfil de la imagen. Para esa asociación se tomaron como referencia los capítulos de la obra de Morgan con las caracterizaciones de cada imagen, a partir de las cuales se definieron las diferentes afirmaciones que fueron agrupadas por columnas, de manera que las afirmaciones asociadas a cada imagen no aparecen de forma consecutiva en el cuestionario. Por ejemplo, las cuestiones vinculadas a la imagen máquina o mecanicismo corresponden con las que ocupan las posiciones 
$1,14,15,28$ y 29. Con esta estrategia se consigue que el entrevistado al responder las diferentes cuestiones en orden consecutivo, no se vea inducido a identificar previamente las caracterizaciones de cada imagen. La Tabla 1 muestra las cuestiones de la encuesta más vinculadas con cada una de las siete imágenes de Morgan.

Tabla 1: Relación de cuestiones de la encuesta vinculadas con las imágenes organizacionales.

\begin{tabular}{|c|c|c|c|c|c|c|c|}
\hline IMAGEN & $\mathbf{M}$ & $\mathbf{O}$ & $\mathbf{S P}$ & $\mathbf{C}$ & ID & FT & PP \\
\hline & 1 & 2 & 3 & 4 & 5 & 6 & 7 \\
\hline \multirow{4}{*}{ Cuestiones } & 14 & 13 & 12 & 11 & 10 & 9 & 8 \\
\hline & 15 & 16 & 17 & 18 & 19 & 20 & 21 \\
\hline & 28 & 27 & 26 & 25 & 24 & 23 & 22 \\
\hline & 29 & 30 & 31 & 32 & 33 & 34 & 35 \\
\hline
\end{tabular}

Fuente: Elaborado por los autores de este artículo

A continuación se explicará la preparación previa que fue necesario realizar sobre los datos recopilados, para, posteriormente, detallar todo el proceso seguido, así como los resultados obtenidos.

\subsection{Pre-procesamiento y Preparación de los Datos}

A partir de las respuestas aportadas por cada empleado al cuestionario, se preparó una base de datos en la que se almacenó información de cada empresa encuestada: sector donde desempeña el negocio, actividad principal desarrollada, tamaño de empresa, ciudad donde radica, cargo del responsable que contesta la encuesta, fecha de realización de la encuesta; y las respuestas a las 35 cuestiones planteadas. Con las respuestas a las 35 cuestiones, se generaron siete valores numéricos con la suma de las puntuaciones de cada una de las cinco cuestiones vinculadas con cada una de las siete imágenes. Estos siete valores se tendrán en cuenta para determinar la imagen que con mayor relevancia proyecta la empresa a juicio del entrevistado.

Un ejemplo de la tabulación de los datos del cuestionario de una empresa es el que se muestra en la Tabla 2. En ella se observa, en la última fila, las sumas de las puntuaciones asociadas a cada una de las imágenes; así por ejemplo, en la empresa asociada a esa Tabla 2 la imagen de mayor relevancia es la correspondiente a "sistema político (SP)".
Tabla 2: Ejemplo de tabulación de respuestas del cuestionario.

\begin{tabular}{|c|c|c|c|c|c|c|c|c|c|c|c|c|c|}
\hline \multicolumn{7}{|c|}{ Nome da Empresa: } & \multicolumn{7}{|c|}{ XXXXXXXXX } \\
\hline \multicolumn{7}{|c|}{ Setor que a empresa atua: } & \multicolumn{7}{|c|}{ FINANCEIRO } \\
\hline \multicolumn{7}{|c|}{ Atividade principal da empresa: } & \multicolumn{7}{|c|}{ PRESTAÇÃO DE SERVIÇOS } \\
\hline \multicolumn{7}{|c|}{ Tamanho: } & \multicolumn{7}{|c|}{ GRANDE } \\
\hline \multicolumn{7}{|c|}{ Ciudade que está localizada: } & \multicolumn{7}{|c|}{ ESTEIO } \\
\hline \multicolumn{7}{|c|}{ Cargo do respondente: } & \multicolumn{7}{|c|}{$\begin{array}{l}\text { COORDENADOR DE } \\
\text { ATENDIMENTO }\end{array}$} \\
\hline \multicolumn{7}{|c|}{ Data: } & \multicolumn{7}{|c|}{ 20/03/2011 } \\
\hline \multicolumn{14}{|c|}{$\begin{array}{l}\text { Tabulação do teste } \\
\mathrm{M}=\text { Máquina } \mathrm{O}=\text { Organismo } \mathrm{SP}=\text { Sistema Político } \mathrm{C}=\text { Cérebro } \\
\mathrm{ID}=\text { Instrumento de Dominação } \mathrm{FT}=\text { Fluxo e Transformação } \\
\mathrm{PP}=\text { Prisão Psíquica }\end{array}$} \\
\hline \multicolumn{2}{|c|}{ M } & \multicolumn{2}{|c|}{$\mathrm{O}$} & \multicolumn{2}{|c|}{ SP } & \multicolumn{2}{|c|}{ C } & \multicolumn{2}{|c|}{ ID } & \multicolumn{2}{|c|}{ FT } & \multicolumn{2}{|c|}{ PP } \\
\hline 01: & 4 & 02: & 3 & 03: & 3 & 04: & 2 & 05: & 2 & 06: & 3 & 07: & 2 \\
\hline 14: & 3 & 13: & 3 & 12: & 3 & 11: & 4 & 10: & 4 & 09: & 4 & 08: & 4 \\
\hline 15: & 4 & 16: & 2 & 17: & 3 & 18: & 4 & 19: & 4 & 20: & 2 & 21: & 3 \\
\hline 28: & 2 & 27: & 2 & 26: & 4 & 25: & 2 & 24: & 2 & 23: & 3 & 22: & 3 \\
\hline 29: & 3 & 30: & 3 & 31: & 4 & 32: & 4 & 33: & 4 & 34: & 3 & 35: & 3 \\
\hline Total & 16 & & 13 & & 17 & & 16 & & 16 & & 15 & & 15 \\
\hline
\end{tabular}

Fuente: Elaborado por los autores de este artículo

Teniendo en cuenta que diferentes empleados pueden tener una percepción diferente sobre su empresa, se calcularon además las valoraciones medias en cada pregunta, de manera que para cada empresa se obtuvieron 35 valores numéricos en el intervalo [1,4] con las valoraciones medias de las 35 cuestiones. De igual manera se realizaron los cálculos medios de los siete valores de relevancia de las imágenes organizacionales. Además se generaron otros siete atributos de tipo booleano, uno por cada imagen, para indicar si la correspondiente imagen es la que obtiene o no la mayor puntuación al sumar las medias de las cinco preguntas asociadas.

A partir de esos cálculos se realizó una clasificación a priori de la imagen de mayor presencia en cada organización, vinculando cada empresa con la imagen que obtenía mayor puntuación global en la suma de las cinco cuestiones más significativas de la misma. En el caso de que varias imágenes obtuvieran la misma puntuación global, se consideraron como empresas con una imagen mixta. Como resultado de ese proceso, se obtuvo una clasificación manual de las empresas, tal 
como muestra la Tabla 3. Como puede apreciarse, la mayoría de las empresas analizadas responden a una imagen "organismo", con más del $34 \%$. El segundo gran grupo corresponde a las empresas con una presencia mixta de imágenes dominantes, con un $23 \%$ de empresas. Entre las empresas con una imagen clara, el segundo grupo corresponde a las que proyectan una imagen "máquina" (14\%).

Tabla 3: Clasificación de las imágenes de las empresas a partir de los cuestionarios

\begin{tabular}{|c|c|}
\hline IMAGEN & NÚmeRo DE EMPRESAS \\
\hline M & 5 \\
\hline O & 12 \\
\hline SP & 1 \\
\hline C & 1 \\
\hline ID & 4 \\
\hline FT & 3 \\
\hline PP & 1 \\
\hline Mixta & 8 \\
\hline Total & 35 \\
\hline
\end{tabular}

Fuente: Elaborado por los autores de este artículo

En resumen, para cada empresa se obtuvieron 43 atributos: los 35 valores medios de las respuestas del cuestionario dadas por sus empleados, los siete atributos booleanos indicando si la imagen es la de mayor relevancia o no, y un último atributo correspondiente a la clasificación realizada tomando como referencia las sumas de las puntuaciones de las cuestiones relacionadas con cada imagen. Debe advertirse, que en caso de que una empresa sea clasificada como de imagen mixta, al menos dos de los atributos booleanos tendrán el valor 1 , los correspondientes a las imágenes de mayor presencia.

La información recopilada no fue sometida a normalización debido a que los valores numéricos de entrada se encuentran todos en la mismo intervalo $[1,4]$.

Es relevante el hecho de que la imagen "flujo y transformación", que el propio Morgan consideraba como la más adecuada en un ambiente competitivo, no parece una presencia predominante en un buen número de empresas; de hecho, en solo tres de las 35 empresas seleccionadas se ve con claridad que dicha metáfora es la más percibida por sus empleados. Sin embargo rasgos característicos de esta metáfora parecen estar presentes en la mayor parte de las empresas pero no muy significativamente, aunque en ocasiones quedan ocultos o enmascarados por otras imágenes que se proyectan con fuerza en las organizaciones. Para justificar esta afirmación se podría decir que si se considera para cada empresa la suma de los valores obtenidos en cada una de las cinco preguntas vinculadas a cada imagen, las dos imágenes que obtienen mayor valor medio en este indicador son "organismo", con un valor medio de 15,30 sobre 20 , y "flujo y transformación" con un valor de 14,83. El resto de imágenes obtienen los valores 14,44 (máquina); 14,01 (instrumento de dominación); 14,00 (cerebro y cultura); 13,04 (sistema político) y 11,68 (prisión psíquica). En definitiva, la imagen flujo y transformación a priori tiene una buena presencia en las empresas analizadas.

\subsection{Aplicación de Técnicas de Explotación de Datos y Metodología}

Para el procesamiento de los datos se utilizó la herramienta open source Weka (Waikato Environment for Knowledge Analysis) de la Universidad de Waikato. Weka es un entorno para experimentación de análisis de datos que contiene múltiples módulos que facilitan el pre-procesamiento, clasificación, agrupamiento y análisis de datos. Una de las primeras labores a realizar fue la selección de atributos, como su nombre indica se trata de seleccionar un subconjunto de los atributos originales buscando una mejora en el desempeño predictivo y construir modelos más eficientes y entendibles. En el caso concreto analizado se trató de averiguar si algunas de las cuestiones planteadas en el cuestionario eran redundantes o irrelevantes para el objetivo de clasificación y por tanto podían ser suprimidas. De las 35 cuestiones planteadas, no todas son igual de válidas a la hora de tratar de identificar la imagen organizacional.

En este trabajo se ha pretendido, por tanto, la utilización de estrategias de selección automática de atributos para identificar las cuestiones con mayor poder discriminante. Weka incorpora una gran variedad de técnicas de selección de atributos que tratan de explorar qué subconjuntos de atributos son los que mejor pueden clasificar la clase de la instancia. Esta selección de atributos tiene dos componentes principales: un método de evaluación que determina 
la calidad del conjunto de atributos para discriminar la clase y un método de búsqueda que determina la forma de realizar la búsqueda de conjuntos.

Además de los evaluadores de subconjuntos de atributos, Weka dispone de prorrateadotes de atributos (AtributeEval) que no seleccionan atributos sino que los ordenan por relevancia de acuerdo a un ranker establecido. En este trabajo se ha utilizado el prorrateador ChiSquareAttributeEval, que evalúa el valor de un atributo mediante el cálculo del estadístico chi-cuadrado con respecto a la clase, y así obtiene el nivel de correlación entre la clase y cada atributo. En concreto se realizaron siete procesos de selección de atributos para establecer un ranking de atributos más relevantes, en cada uno de esos procesos se consideró como clase el respectivo atributo booleano que indica si la empresa tenía o no la correspondiente imagen como imagen dominante. En definitiva, se obtuvieron siete rankings diferentes que se condujeron al mostrado en la Tabla 4, resultado de calcular las medias de los valores del evaluador de atributos en cada ranking individual. En dicha tabla se muestran únicamente los atributos que obtuvieron un valor no nulo en dicha media.

Tabla 4: Ranking de cuestiones más relevantes de acuerdo al prorrateador de atributos ChiSquaredAttributeEval

\begin{tabular}{|c|c|c|c|c|c|c|c|}
\hline ORDEN & $\begin{array}{l}\text { VALOR DEL } \\
\text { RANKING }\end{array}$ & Cuestión & $\begin{array}{l}\text { IMAGEN ASO- } \\
\text { CIADA }\end{array}$ & ORden & $\begin{array}{l}\text { VALOR DEL } \\
\text { RANKING }\end{array}$ & Cuestión & $\begin{array}{c}\text { IMAGEN ASO- } \\
\text { CIADA }\end{array}$ \\
\hline 1 & 3,63286 & 13 & $\mathrm{O}$ & 8 & 1,58443 & 30 & $\mathrm{O}$ \\
\hline 2 & 3,40586 & 7 & $\mathrm{PP}$ & 9 & 1,58200 & 14 & M \\
\hline 3 & 3,23229 & 31 & SP & 10 & 1,40757 & 26 & SP \\
\hline 4 & 2,87071 & 4 & $\mathrm{C}$ & 11 & 1,24757 & 27 & $\mathrm{O}$ \\
\hline 5 & 1,86200 & 29 & M & 12 & 1,11114 & 20 & FT \\
\hline 6 & 1,68414 & 10 & ID & 13 & 1,11100 & 1 & M \\
\hline 7 & 1,68414 & 22 & PP & 14 & 1,05257 & 21 & PP \\
\hline
\end{tabular}

Fuente: Elaborado por los autores de este artículo

En definitiva, se optó por seleccionar únicamente 14 de las cuestiones del test inicial, en concreto las mostradas en la Marco 2. Como puede comprobarse, comparando con la agrupación de cuestiones realiza a priori en grupos de cinco cuestiones por imagen organizacional, de todos los grupos se ha seleccionado automáticamente al menos una cuestión. Analizando las preguntas que han sido seleccionadas de manera automática por el algoritmo de selección de rasgos, se observa que para tres imágenes concretas se ha seleccionado únicamente una pregunta, en concreto para la imagen "cerebro y cultura" (cuestión 4), "instrumento de dominación" (cuestión 10) y "flujo y transformación" (cuestión 20). Las causas pueden ser varias, por un lado en algunos casos existen preguntas cuyas respuestas han tenido poca variabilidad entre los encuestados; por ejemplo, la cuestión 19, asociada a la imagen ID, tuvo un valor promedio de 3,99 en las 35 empresas consideradas, evidentemente esa cuestión no tiene ningún valor discriminante a la hora de analizar las imágenes. En otros casos, existe fuerte correlación entre las respuestas dadas a preguntas del mismo grupo, lo que hace que el algoritmo únicamente requiera seleccionar una sola pregunta por grupo. 


\begin{tabular}{|c|c|c|}
\hline $\mathbf{N}^{\mathbf{o}}$ & Cuestión & $\begin{array}{l}\text { IMAGEN } \\
\text { ASOCIADA }\end{array}$ \\
\hline 1 & $\begin{array}{l}\text { Existe estandarización de los procedimientos, } \\
\text { operaciones y procesos. }\end{array}$ & M \\
\hline 4 & Existe una acción flexible y creativa. & $\mathrm{C}$ \\
\hline 7 & $\begin{array}{l}\text { Los individuos y los grupos tienden a tener un } \\
\text { comportamiento infantil. }\end{array}$ & $\mathrm{PP}$ \\
\hline 10 & $\begin{array}{l}\text { Las personas trabajan bajo estrés y presión } \\
\text { constantes. }\end{array}$ & ID \\
\hline 13 & $\begin{array}{l}\text { La organización tiene en cuenta las motivaciones } \\
\text { y necesidades de las personas. }\end{array}$ & $\mathrm{O}$ \\
\hline 14 & $\begin{array}{l}\text { Existen normas rígidas y uniformidad en el } \\
\text { comportamiento de las personas. }\end{array}$ & M \\
\hline 20 & $\begin{array}{l}\text { La organización se beneficia más del flujo de } \\
\text { acontecimientos externos (medio ambiente) que } \\
\text { de planteamientos rígidos. }\end{array}$ & FT \\
\hline 21 & $\begin{array}{l}\text { Hay muchos tabúes y prejuicios en la } \\
\text { organización. }\end{array}$ & $\mathrm{PP}$ \\
\hline 22 & $\begin{array}{l}\text { Las relaciones entre superiores y subordinados } \\
\text { tienden a contener elementos de amor y odio. }\end{array}$ & $\mathrm{PP}$ \\
\hline 26 & $\begin{array}{l}\text { Las intrigas interpersonales consumen energía } \\
\text { y distraen la atención de los flujos productivos. }\end{array}$ & SP \\
\hline 27 & $\begin{array}{l}\text { Las metas organizacionales y las necesidades } \\
\text { de las personas pueden ser simultáneamente } \\
\text { atendidas. }\end{array}$ & $\mathrm{O}$ \\
\hline 29 & $\begin{array}{l}\text { Se espera que la organización opere de manera } \\
\text { rutinaria, eficiente, confiable y predecible. }\end{array}$ & M \\
\hline 30 & $\begin{array}{l}\text { Los empleados son vistos como recursos } \\
\text { valiosos que pueden contribuir de manera rica } \\
\text { y variada en las actividades de la organización, } \\
\text { a condición de que alcancen sus necesidades } \\
\text { y motivaciones. }\end{array}$ & $\mathrm{O}$ \\
\hline 31 & Los rumores y los chismes son frecuentes. & $\mathrm{SP}$ \\
\hline
\end{tabular}

Marco 2: Ranking de cuestiones más relevantes de acuerdo al prorrateador de atributos ChiSquaredAttributeEval Fuente: Elaborado por los autores de este artículo

Una vez seleccionado un subconjunto de cuestiones, el siguiente objetivo fue realizar una explotación de dichos datos. Weka permite elegir dos tipos de técnicas de explotación de minería de datos: técnicas supervisadas y no supervisadas, especializadas en descubrir patrones o tendencias de los datos para la extracción de información valiosa. Una de las técnicas no supervisadas es el agrupamiento o clustering, que busca agrupar un conjunto de datos en subconjuntos o grupos según sus similitudes. En cambio, la clasificación supervisada enfoca el problema de clasificación de otra manera, parte de una muestra de entrenamiento, o conjunto de aprendizaje, con una serie de elementos ya clasificados en unas categorías predefinidas y conocidas, para a partir de ella ser capaz de clasificar nuevos elementos.

Weka implementa un buen número de algoritmos de clustering, uno de los algoritmos más simples pero también eficientes es el de las k-medias. Según Aluja (2001), excepto en ciertos problemas específicos y difíciles, la mayoría de problemas abordados en minería de datos dan resultados comparables cualquiera que sea la técnica utilizada. En su concepción más simple, el algoritmo de las k-medias se basa en elegir aleatoriamente $k$ vectores que actúen como centroides de cada cluster y realizar un proceso inicial de asignación de cada objeto al cluster asociado al centroide más próximo de acuerdo a la medida de similitud establecida. Tras esa asignación inicial, se recalculan los centroides de cada cluster y se vuelve a realizar el proceso de asignación. El algoritmo finaliza cuando en una de las iteraciones no se ha producido ningún cambio en la asignación del cluster o cuando se realizan un número de iteraciones preestablecido de antemano. El principal inconveniente de este algoritmo es la necesidad de proporcionarle de antemano el número de clusters a crear; sin embargo, en este trabajo como el objetivo es tratar de identificar de manera automática las imágenes organizativas de Morgan, se puede tomar como valor del parámetro $\mathrm{k}$ el número de éstas, es decir siete.

En el trabajo se ha aplicado el algoritmo de las k-medias sobre los datos de las 35 empresas del estudio correspondientes a las 14 cuestiones seleccionadas, tratando de identificar subgrupos homogéneos dentro de la población de empresas. El atributo de clasificación a priori a partir de las puntuaciones obtenidas en cada grupo de cuestiones se utilizó para comparar con los resultados del algoritmo. En la próxima sección se resumen los resultados y las conclusiones del análisis.

\subsection{Resultados y Análisis}

Tras aplicar el algoritmo de las k-medias, los resultados obtenidos son los que se resumen en la Tabla 5. Dicha tabla muestra los siete grupos, con el número de empresas asignadas a cada uno y los centroides de cada grupo. Estos centroides corresponden a los vectores cuyas coordenadas son los valores medios dentro de 
cada grupo de los 14 rasgos seleccionados para realizar el proceso de clustering. Para llegar a construir los grupos, fueron necesarias cinco iteraciones del algoritmo de las k-medias. Como puede apreciarse la mayor parte de las empresas se distribuyen en 3 grupos, los correspondientes a los clusters de índices 0,3 y 6 . Los otros cuatro grupos son o bien empresas individuales o grupos con un número reducido de elementos.

Tabla 5: Resultados del agrupamiento con el algoritmo de las k-medias. Valores medios de las respuestas a las preguntas seleccionadas de cuestionario en cada uno de los grupos

\begin{tabular}{|c|c|c|c|c|c|c|c|}
\hline $\begin{array}{l}\text { Clus- } \\
\text { ters }\end{array}$ & 0 & 1 & 2 & 3 & 4 & 5 & 6 \\
\hline $\begin{array}{c}\mathrm{N}^{\mathrm{o}} \mathrm{de} \\
\text { em- } \\
\text { presas }\end{array}$ & $\begin{array}{c}13 \\
(37 \%)\end{array}$ & $\begin{array}{c}1 \\
(3 \%)\end{array}$ & $\begin{array}{c}3 \\
(9 \%)\end{array}$ & $\begin{array}{c}7 \\
(20 \%)\end{array}$ & $\begin{array}{c}3 \\
(9 \%)\end{array}$ & $\begin{array}{c}1 \\
(3 \%)\end{array}$ & $\begin{array}{c}7 \\
(20 \%)\end{array}$ \\
\hline \multicolumn{8}{|c|}{ Cuestión } \\
\hline 1 & 3.4936 & 3.6667 & 3.25 & 3.1786 & 2.8889 & 4 & 3.8571 \\
\hline 4 & 3.0897 & 3.3333 & 2.6667 & 3.1786 & 3.0833 & 2.6667 & 2.3929 \\
\hline 7 & 1.6538 & 1 & 2.2778 & 2.131 & 2.7778 & 1.6667 & 2.2143 \\
\hline 10 & 2.391 & 2 & 2.3056 & 2.8333 & 3.6944 & 4 & 3.5 \\
\hline 13 & 3.1667 & 3 & 1.8889 & 3.6667 & 2.6111 & 2.6667 & 2.9643 \\
\hline 14 & 2.4744 & 1 & 2.1111 & 2.6667 & 2.5556 & 4 & 2.4643 \\
\hline 20 & 2.5192 & 2.3333 & 2.8889 & 2.4405 & 3.1111 & 2 & 2.6786 \\
\hline 21 & 1.5064 & 1.3333 & 2.4444 & 1.7619 & 2.6111 & 4 & 2 \\
\hline 22 & 1.5577 & 1 & 2.5833 & 2.0833 & 2.7222 & 3 & 2.0357 \\
\hline 26 & 1.9167 & 3.3333 & 3 & 2.5119 & 3.3889 & 3.3333 & 2.6429 \\
\hline 27 & 3.0705 & 3 & 2.3056 & 3.3452 & 2.7778 & 2.6667 & 2.5 \\
\hline 29 & 3.4423 & 3 & 2.9444 & 2.7619 & 3.1111 & 4 & 3.25 \\
\hline 30 & 3.3462 & 3.6667 & 1.6111 & 3.7262 & 2.7778 & 2.6667 & 2.9643 \\
\hline 31 & 1.891 & 1.6667 & 3.4167 & 2.5714 & 3.3333 & 3 & 2.6429 \\
\hline
\end{tabular}

Fuente: Elaborado por los autores de este artículo

Al haber proporcionado a Weka la clasificación a priori de las empresas de acuerdo a la puntuación global de las encuestas por grupos de preguntas, a la hora de mostrar los resultados el propio software realiza una asignación automática de la categoría asignada a cada cluster. En concreto, la Tabla 6 muestra dichas asignaciones; como puede comprobarse únicamente dos imágenes de Morgan parecen tener asignado un cluster con claridad y con un número significativo de empresas, siendo el grupo más numeroso el que responde a una imagen mixta.

Tabla 6: Categorías asignadas a cada grupo.

\begin{tabular}{|c|c|c|c|}
\hline Cluster & $\begin{array}{c}\text { Número DE } \\
\text { EMPRESAS }\end{array}$ & $\mathbf{\%}$ & $\begin{array}{c}\text { CATEGoría } \\
\text { ASIGNADA }\end{array}$ \\
\hline 0 & 13 & 37 & MIX \\
\hline 1 & 1 & 3 & Sin asignación \\
\hline 2 & 3 & 9 & Sin asignación \\
\hline 3 & 7 & 20 & O \\
\hline 4 & 3 & 9 & SP \\
\hline 5 & 1 & 3 & Sin asignación \\
\hline 6 & 7 & 20 & ID \\
\hline
\end{tabular}

Fuente: Elaborado por los autores de este artículo

Según los resultados tras aplicar el algoritmo de clustering, las empresas estarían representadas $\mathrm{u}$ asociadas principalmente a dos tipos de imágenes organizacionales: $\mathrm{O}, \mathrm{ID}$, sin embargo, la mayor parte de ellas responden a imágenes híbridas que combinan características de dos o más imágenes organizacionales. Entre las empresas con una imagen más clara, predominan las que responden a la metáfora "organismo", aspecto éste que coincide con el observado en la clasificación a priori de la Tabla 4. Las empresas que responden a la imagen de "instrumento de dominación" también reciben la asignación de un grupo en el algoritmo. Puede llamar la atención el hecho de que la metáfora "máquina", que en la clasificación a priori tenía un número mayor de empresas, no recibe un grupo específico y esas empresas se distribuyen entre los diferentes clusters.

Analizando los valores de los centroides de los tres clusters principales de la Tabla 5 y teniendo en cuenta la vinculación de cada rasgo con una de las imágenes de Morgan (ver Marco 2), se puede hacer un análisis de la imagen predominante en cada grupo. Así por ejemplo, en el cluster 0 , el que agrupa a empresas principalmente con una imagen mixta, las preguntas que obtienen mayor puntuación media son las más vinculadas con las imágenes $\mathrm{O}, \mathrm{My} \mathrm{C}$, con valores muy próximos todas ellas. En el cluster de índice 3 el mayor valor se obtiene en preguntas vinculadas a la imagen $\mathrm{O}$, y en menor medida la imagen $\mathrm{C}$. Finalmente, en el 
cluster de índice 6 la puntuación máxima corresponde a la imagen ID, y en menor medida a la imagen $\mathrm{M}$.

En definitiva, la mayor parte de las empresas no se puede considerar que respondan a una única y clara imagen organizacional. Todas ellas tienen rasgos o características propias de diferentes imágenes. Sí que es cierto que las imágenes que parecen percibirse con más claridad son los "organismos" y los "instrumentos de dominación". Las imágenes "máquina" y "cerebro" parecen estar presentes en cierto grado en la mayor parte de las empresas, aunque muchas veces combinadas con otras metáforas lo que dificulta su identificación clara o la percepción de esa imagen por los empleados.

Por tanto, si se tiene en cuenta la identificación automática del algoritmo de las imágenes empresariales, se podría decir que predominan tres perfiles de empresas en las que si bien se conjugan características de las diferentes imágenes propuestas por Morgan, hay claramente predominio de las imágenes $\mathrm{O}$ e ID $y$ en otras no es posible percibir de forma clara una única imagen.

\section{Conclusiones}

Este trabajo ha evidenciado que las imágenes o metáforas de Morgan (1996) en las empresas es una adecuada forma de comprender la cultura organizacional, y las relaciones funcionales en la realización de actividades en sus procesos de negocio. El enfoque desarrollado en el trabajo ha permitido diagnosticar y analizar estas situaciones culturales en una muestra de empresas del estado de Rio Grande del Sur. Se han utilizado conceptos y técnicas cuantitativas de análisis de datos basado en data mining e implementadas a través del software Weka.

El trabajo realizado puede dividirse en dos fases; en la primera se desarrolló un instrumento de análisis de empresas para realizar una clasificación a priori de la imagen predominante. Este instrumento se basa en la aplicación de un cuestionario con 35 cuestiones extraídas de la obra de Morgan (1996), dividiendo las 35 cuestiones en siete grupos con cuestiones directamente relacionadas con cada una de las imágenes organizacionales de Morgan. Cada grupo está constituido por cinco cuestiones, lo que permite realizar comparaciones cualitativas de las puntuaciones globales obtenidas por cada empresa en cada grupo. En esta primera fase se realizaron un total de 119 entrevistas con personal de 35 empresas diferentes, cada empleado realizó una valoración cualitativa sobre el estado en su organización de cada cuestión, realizándose posteriormente valoraciones medias de las opiniones de empleados y directivos de una misma organización.

En la clasificación a priori realizada se pudo comprobar que en un buen número de empresas no existía una imagen claramente dominante, y en ocasiones se percibían rasgos característicos de diferentes imágenes. En cualquier caso, sí que se observaba que la imagen que proyectan con más claridad las empresas estudiadas es la de "organismo", y en menor medida "máquina", "instrumento de dominación" y "flujo y transformación". Se podría por tanto decir que en la mayor parte de las empresas analizadas se percibe que las necesidades humanas son atendidas conjuntamente con las necesidades de la empresa, una adecuada adaptación e evolución empresarial y buena salud organizacional, rasgos propios de la metáfora "organismo" $(\mathrm{O})$. En menor medida se perciben rasgos como precisión mecánica en disciplina laboral, estandarización, cumplimento de horarios y de tareas (M), represión, imposición de valores y voluntad, cumplimiento, dominación social, uso y explotación de los empleados, mantenimiento del poder, fuerza, explotación y cierta discriminación organizacional (ID), o cambio constante, equilibrio dinámico, flujo, auto-organización (FT).

En una segunda fase, se optó por la aplicación de técnicas de minería de datos para refinar el instrumento de análisis y automatizar la identificación de grupos de empresas relacionadas. Así, se observó que gracias a las estrategias de selección de rasgos se pudo identificar 14 cuestiones clave que pueden ser utilizadas para percibir las imágenes. Con los valores en cada empresa de esas cuestiones se aplicó un algoritmo de clasificación no supervisada, el algoritmo de las k-medias, y se pudo comprobar de nuevo que el grupo más numeroso coincide con el de empresas con metáforas mixtas, obteniéndose de nuevo un grupo vinculado con la metáfora "organismo" y otros dos con "sistema político" e "instrumentos de dominación". De esta manera, es posible afirmar que también se incorpora al perfil de los análisis las características de "sistema político" (SP), empresas caracterizadas por la consideración de la empresa como un sistema político 
o de gobierno con relaciones significativas de poder, intereses y conflictos.

El diagnóstico y los análisis matemáticos generados son importantes para la gestión de la cultura y del comportamiento empresarial, ya que con las metáforas o imágenes es posible trabajar mejor en las correcciones de los objetivos organizacionales. También es posible direccionar mejor tanto el entrenamiento funcional como la mejoría de competencias individuales.

Con este trabajo se ofrece a la comunidad científica un método que establece una relación de diagnóstico y análisis robusto de un paradigma metodológico positivista. Para futuros trabajos se recomienda una ampliación del análisis realizado, aumentando el tamaño de la muestra y realizando estudios particulares por sectores específicos. Buscando igualmente un diagnóstico de la situación de la metáfora "flujo y transformación" que ya en la década de los 90 Morgan anticipaba como un referente para las empresas competitivas, y que sin embargo, en los estudios realizados sobre la muestra no ocupa un papel destacado en las empresas de RS.

\section{Referencias}

ALUJA, T. Gestão da cultura organizacional. Apostila FGV Management - SIGA - Sistema de Informação e Gestão Acadêmica da Fundação Getúlio Vargas, RJ: FGV, 2008.

\section{Some questions concerning images of} organization: an Interview with Gareth Morgan. Edited transcript of a teleconference with Dr. Gareth Morgan and the University of Alberta doctoral students in Educational Administration, November 7, 1996. Disponble: <www. imaginiz.com/provocative/metaphors/questions.html>. Acceso: 10 jul. 2011.

La minería de datos, entre la estadística y la inteligencia artificial. QUESTIIO, Barcelona, v. 25, 3, p. 479-498, 2001.

CAPRA, F. A Teia da vida: uma nova compreensão científica dos seres vivos. São Paulo: Cultrix, 1996.
CORSO, C. Aplicación de algoritmos de clasificación supervisada usando Weka. Congreso: Información y Comunicación para la Sociedad del Conocimiento. CNIT2009. Argentina, 2009. Disponible: < http:// www.investigacion.frc.utn.edu.ar/labsis/Publicaciones/ congresos_labsis/cynthia/CNIT_2009_Aplicacion_ Algoritmos_Weka.pdf>. Acceso: $1^{\circ}$ mayo 2011.

ETZIONI, A. Análise comparativa de organizações complexas. Rio de Janeiro: Zahar Editores, 1974.

FERRI, C.; RAMÍREZ, M. J.; HERNÁNDEZ, J. Introducción a la minería de datos. Prentice Hall, 2004.

\section{FLEURY, M.; FISCHER, R. Cultura e poder nas} organizações. São Paulo: Atlas, 1996.

FREITAS, M. Cultura organizacional: formação, tipologias e impactos. São Paulo: Makron, 1991.

\section{GRANDÍO, A. Empresa, mercado y necesidades:} una Síntesis en Ciencias Sociales. Tesis Doctoral. Cap. 4. 1996.

HELLRIEGEL, D.; SLOCUM, J. W. Comportamiento organizacional. México: Thomson, 2004.

JOHANN, S. L. Gestão da cultura corporativa: como as organizações de alto desempenho gerenciam a sua cultura organizacional. São Paulo: Saraiva, 2004.

Gestão da cultura organizacional. Apostila FGV Management - SIGA - Sistema de Informação e Gestão. Rio de Janeiro: Acadêmica da Fundação Getúlio Vargas (FGV), 2008.

KATZ D.; KAHN, R. Psicologia social das

organizações. 2. ed. São Paulo: Atlas, 1978.

LAWLEY, J. Metaphors of Organisation. 2001. Disponible: $<$ http://www.cleanlanguage.co.uk/Metaphors-of-Orgs-1. html>. Acceso: 24 mayo 2011.

MCCRACKEN, G. Chief culture office: como a cultura pode determinar o sucesso ou o fracasso da organização. São Paulo: Editora Aleph, 2011.

MINARELLI, J. Empregabilidade: o caminho das pedras. São Paulo: Gente, 1995. 
MORGAN, G. Images of organization. 1. ed. Newbury Park, CA: SAGE Publications, 1996.

MORGAN, G. Paradigmas, Metáforas e Resolução de Quebra-Cabeças na Teoria das Organizações. Revista de Administração de Empresas, São Paulo, n.1, v. 45, p. 58-71, jan.-mar. 2005.

MORGAN, G. Images of organization. 3. ed. Thousand Oaks, CA: SAGE Publications, 2006.

PINKER, S. The language instinct: how the mind creates language. Cambridge, MA: Cambridge University Press, 1994.

SCHEIN, E. H. Organizational Culture. American Psychologist, San Francisco, v. 45, n. 2, 1990.

TABER, T. D. Using metaphors to teach organization theory. Journal of Management Education, Australia, v. 31, n. 4, p. 541-545, 2007.

\section{TAYLOR, F. W. Princípios de administração}

científica. São Paulo: Atlas, 1980. 134 p.

\section{VON BERTALANFFY, L. Teoria geral dos sistemas.}

Petrópolis: Vozes, 1972.

WEBER, M. Ensaios de sociologia. 5. ed. Rio de Janeiro: LTC editora, 2002.

WITTEN, I.; FRANK, E. Data mining. Practical Machine Learning Tools and Techniques. Morgan Kaufmann Publishers, EE. UU. 2005. 


\section{Anexo A - Cuestionario de iden- tificación de rasgos de imágenes organizacionales}

\begin{tabular}{l|l|}
\hline 1 & $\begin{array}{l}\text { Existe estandarización de los procedimientos, operaciones } \\
\text { y procesos. }\end{array}$ \\
\hline 2 & $\begin{array}{l}\text { Los cambios en la organización son, por lo general, una } \\
\text { especie de reacción a los cambios que se han producido en } \\
\text { el entorno macroeconómico de los negocios. }\end{array}$ \\
\hline 3 & $\begin{array}{l}\text { Los administradores frecuentemente hablan de autoridad, } \\
\text { poder y relaciones superior-subordinado. }\end{array}$ \\
\hline 4 & $\begin{array}{l}\text { Existe una acción flexible y creativa. } \\
\text { Trabajar en circunstancias y condiciones inadecuadas es } \\
\text { considerado como prueba de lealtad a la organización. }\end{array}$ \\
\hline 6 & $\begin{array}{l}\text { La organización se considera como parte de un sistema } \\
\text { mayor, donde existe interdependencia con la comunidad, } \\
\text { los proveedores, e incluso la competencia. }\end{array}$ \\
\hline 7 & $\begin{array}{l}\text { Los individuosy los grupos tienden a tener un comportamiento } \\
\text { infantil. }\end{array}$ \\
\hline 8 & $\begin{array}{l}\text { Los logros del pasado son constantemente citados como } \\
\text { referencia y como ejemplo para hacer frente a situaciones } \\
\text { de adversidad presentes y futuras. }\end{array}$ \\
\hline 11 & $\begin{array}{l}\text { La organización se desarrolla en armonía y en equilibrio con } \\
\text { su entorno macroeconómico. }\end{array}$ \\
\hline 10 & $\begin{array}{l}\text { Las personas trabajan bajo estrés y presión constantes. } \\
\text { de acciones. }\end{array}$ \\
\hline 12 interés.
\end{tabular}

13 La organización tiene en cuenta las motivaciones y necesidades de las personas.

14 Existen normas rígidas y uniformidad en el comportamiento de las personas.

La organización posee y utiliza una gran cantidad de reglas,

15 normas y regulaciones sobre aspectos operacionales del negocio.

16 Existen abundantes redes de relaciones entre individuos y grupos.

17 La delegación de poderes a los niveles operacionales tiende a ser muy restrictiva.

18 El feedback negativo se recomienda para proporcionar la corrección en la dirección de la organización.

19 La organización espera una total devoción y dedicación de sus empleados.

20 La organización se beneficia más del flujo de acontecimientos externos (medio ambiente) que de planteamientos rígidos.

21 Hay muchos tabúes y prejuicios en la organización.
22 Las relaciones entre superiores y subordinados tienden a contener elementos de amor y odio.

23 La supervivencia a largo plazo se logrará en colaboración con las fuerzas que actúan en el macro-ambiente y no contra él.

24 Despedir personas y recortar actividades es una parte del juego.

25 Las personas, en su mayoría, piensan que influyen en el destino de la organización.

26 Las intrigas interpersonales consumen energía y distraen la atención de los flujos productivos.

27 Las metas organizacionales y las necesidades de las personas pueden ser simultáneamente atendidas.

28 En la organización se piensa: iAquí es el reino de la burocracia!

29 Se espera que la organización opere de manera rutinaria, eficiente, confiable y predecible.

Los empleados son vistos como recursos valiosos que pueden contribuir de manera rica y variada en las actividades de la organización, a condición de que alcancen sus necesidades y motivaciones.

31 Los rumores y los chismes son frecuentes.

32 La organización tiende a ofrecer respuestas rápidas a los cambios en su macro-ambiente.

33 La organización valora los ejecutivos que muestran una marcada fidelidad a la forma de ser de la empresa.

En el proceso de toma de decisiones estratégicas, por lo 34 general la organización deja un enfoque simplista y prefiere tener en cuenta la complejidad del tema.

Las personas están comprometidas con la organización

35 porque perciben su pertenencia a algo más grande, que trasciende a su existencia y limitaciones individuales. 